\title{
Enabling Theory into Practice: Making Sense of the 'Why' and the 'How' in the Early Years
}

\author{
Karen McInnes ${ }^{1}$, Amanda Thomas ${ }^{2}$, Claire Pescott ${ }^{2}$, Cath Jones ${ }^{2}$, \\ Rhiannon Packer ${ }^{3}$, Philippa Watkins ${ }^{2}$ \\ ${ }^{1}$ Norland College, UK \\ ${ }^{2}$ University of South Wales, UK \\ ${ }^{3}$ Cardiff Metropolitan University, $U K$
}

\begin{abstract}
The authors delivered and facilitated a panel discussion at the London International Conference on Education (LICE-2017) based on a recently published book [1]. It is recognised that high-quality early years education is of prime importance in enabling our youngest children to develop and learn to their full potential. To achieve this, they require high quality early years practitioners to support their learning and development. Early years practitioners need to integrate theory, the 'why', with practice, the 'how', across all areas of the curriculum. This paper provides a discussion on selected curriculum areas: Literacy, Mathematics and Science alongside a discussion on current policy and the importance of play and playfulness. It includes reference to current research and case study material to demonstrate how the integration of 'why' and 'how' might be achieved during the training of early years students and practitioners. In addition, it reports recent feedback from a short survey undertaken with early years students using the book and these materials in their training. Students reported greater understanding of concepts and theories and how they could incorporate this within their practice as well as feeling they were receiving extra in-class time from having a text written by their tutors.
\end{abstract}

\section{Introduction}

It is argued that the early years of a child's education are critical to their lifelong development and therefore our youngest children deserve the highest quality early childhood education possible. To achieve this, it is necessary that early years practitioners involved in the delivery of high quality early years education are able to understand and reflect on theory and integrate this meaningfully in practice. Subject benchmark statements for those studying in the field of early years or early childhood studies state that students should consider theory in relation to the implications for practice and should be able to evaluate and develop appropriate pedagogical practices [2]. This linking of theory and practice is integral throughout the time of studying and beyond. In addition, a recent early years' review stated that early years students and practitioners need to be able to reflect critically on practice and theory in order to gain a deep understanding of practice and work within the complexity and messiness of early year's practice [3].

The panel discussion for the conference, and this paper, aimed to explore the importance of integrating theory and practice across the early years and early primary phase. The ideas and debates presented in the panel discussion were based on a book, written by the presenters, which discussed this in more detail [1]. The underpinning research integrated both the 'why' and the 'how' by giving a theoretical background to areas of the curriculum whilst discussing how this looked in practice. A range of curriculum areas were discussed: Literacy, mathematics, science, creativity, social and emotional development and outdoor play. In addition, a contextual framework of different UK early years curricula was provided along with overarching themes of child development and play and playfulness as understanding of these themes is core to early years practice.

To demonstrate how theory can be integrated into practice, case studies were used to exemplify this practice. It is acknowledged that case-based pedagogy is an effective approach when putting theory into practice [4] and should be used more frequently in early education programmes when trying to bridge the theory-practice divide. Whilst there is not scope within this paper to reproduce the case studies, the learning from them has been discussed. A unique aspect of demonstrating how theory can be integrated into practice was through each curriculum area being written by an early years practitioner and an academic working together. One recognised aspect of good practice within teaching is when tutors and students collaborate together and this was exemplified by the practice of a practitioner and academic working together as a mini learning community thus providing a positive role model for students.

Although an overview of all early years UK curricula was presented to contextualize early years practice the discussion within each curriculum area was based on the English Early Years Foundation Stage (EYFS) [5] curriculum and the Welsh Foundation Phase curriculum (EYFP) [6]. Whilst 
there is much literature discussing practice within the English context there is a dearth of literature located within the Welsh curriculum. Since 2008 the Welsh Government has broken away from the rest of the UK in its education delivery. The Foundation Phase (FP) for 3--7 year olds has been introduced as a child centred and experiential pedagogy where children learn through play. The implementation of this playbased curriculum required a shift in focus from an adult led, didactic approach to a much more shared ethos, where the practitioner and child work together using an experiential pedagogy. As a result, it has much to offer early years understanding and practice across the UK. This paper will provide contextual information on current UK early years curricula frameworks followed by a discussion of how play and playfulness may be seen as a form of communication and underpin teaching and learning across different curriculum areas. Integrating theory and practice within the core curriculum areas of literacy, mathematics and science will then by explored. Finally, the results of a short survey of students focused on their use of the book will be discussed.

\section{UK early years curricula}

This chapter provided a context for the book and panel discussion by locating the discussion of the different curriculum areas within the UK context. It compared and contrasted the similarities and differences between the different curricula and how they viewed and used play when working with young children. It is essential for practitioners that the distinction between the terms 'pedagogy' and 'curriculum' are established, as they are sometimes used interchangeably incorrectly. In simplistic terms 'pedagogy' refers to the art or the science of teaching, the mechanics or process that underpins it. It can also be viewed as a cohesive entity of theory and practice that draws on philosophy, psychology and social science [7]. It is fundamentally the process itself of learning and teaching and the systems that are in place to facilitate this. A curriculum is a framework, a guide to be utilised and implemented in a practical way, it should provide necessary breadth and coverage of all areas of learning, incorporate differentiation, facilitate assessment and promote a holistic, cohesive approach. Early years curriculum models in the UK have varying differences and diverse underlying beliefs and values, however play is the common denominator between the four UK curricula. Practitioners have an ethical and professional responsibility to interpret the framework and make subsequent informed decisions as well as the children's response to this, which is dependent on a multi-faceted dimension of diversity e.g. gender, ethnicity, religion, culture, social class and additional or special needs [8].
There are parallels between the UK curricula in terms of areas of learning, implementation of assessment and the overarching emphasis of play being central to early years learning and teaching. The age ranges for each curriculum are wide ranging with the EYFS (England) commencing at birth and the Curriculum for Excellence (Scotland) being longitudinal in nature (up to 18 years). Although Wales has a separate curriculum for Early Years (37 years) currently this will be changing imminently; A Curriculum for Wales - A Curriculum for Life will be piloted from 2018 and will adopt a cross key stages approach from 3 - 16 years. Each curriculum has areas of learning rather than distinct and separate subjects, whilst they have different titles, similarities occur with an emphasis on personal development and literacy and numeracy being high on the agenda. In Wales, a Welsh Development component is additional to reflect the bilingual culture. The philosophy of play is a distinctive feature of all UK curricula and consequently demonstrates the importance of this pedagogy to children's development. The four UK frameworks have their own version of what constitutes 'educational play' but can be seen as an approach in school settings across the country. In Scotland, play is integral to the early year's curriculum which endeavors to create an environment that provides rich play experiences and ensures the needs of children and young people are met. Similarly for Northern Ireland a stipulation is made to ensure that play is the adopted approach for academic and social development and is integral to the curriculum. The Early Years Foundation Stage in England also emphasises the importance of the play environment but also acknowledges that each child is unique and practitioners need to get to know each individual child. Likewise a play based approach and active learning is advocated in Wales and is fundamental to the Foundation Phase. An essential part of this curriculum is a mix of adult and child led play and that all stakeholders are aware of this premise. However it is important to note that the rhetoric and reality of play is an issue across all UK curricula and more formalised and didactic approaches are becoming common practice. Assessment is a key difference between the UK curricula: in England children have a baseline assessment in Reception, a phonics screening test at the end of Year 1 and SATs in Year 2. In Scotland general screening takes place in P1 (Reception) to assess children's ability on starting school. There are standardised assessments in reading, mathematics and spelling every year from P2 (Year 2). In Wales, children take national Reading and Numeracy tests at Year 2, this has caused much controversy and whether this is conducive to a play based curriculum [9]. In Northern Ireland, the biggest difference occurs with children being assessed every year 
through teacher assessment and planned tasks and activities rather than formalised tests.

Policy and pedagogy in this country do not appear in isolation; influences have been drawn from other international perspectives and this continues to evolve as practitioners need to understand that there are many ways of implementing a curriculum and the delivery is inextricably bound in the how play is understood and valued. Two approaches that have been fundamental to the inception of UK play based curricula are the Te Whariki (New Zealand) approach and the Reggio Emilia (Italy) approach which both demonstrate a strong emphasis of child led engagement, the creative arts and a thematic underpinning. Bearing this in mind, practitioners in the UK need to work in a collegial way ensuring a wealth of play opportunities are provided and that all areas of learning are considered to ensure a broad and balanced curriculum is provided to our young learners. An enabling environment needs to be stimulating, challenging and planned for appropriately and build a solid foundation for future learning. It is apparent that curriculum frameworks are influenced by both political and global agendas, they are continually evolving and do not stand in isolation of each other.

\section{Play and playfulness}

The chapter on play and playfulness was an underpinning chapter as the authors considered this to be an important aspect of teaching all curriculum areas. The view of play presented in the chapter and the panel discussion was based on play and playfulness being used as a form of communication rather than the traditional view of it being a vehicle for learning with its inherent risk of being hijacked to suit adult teaching purposes rather than children's learning. Play and playfulness provide the foundation for learning and development in the early years however, it is important to differentiate between play and playfulness theoretically in order for playful educators to engage in playful practice with young children. Play underpins early years curricula guidance across the world however, its complexity is not really acknowledged or addressed. There are many theories as to why children play including: play being a form of recreation, play as a re-creation of human evolution, play as a behaviourally conditioned response to others and play as a cultural activity. Within an educational context play has traditionally been seen as a vehicle for learning and this is the underpinning theoretical stance as to why children play that is communicated in the EYFS and EYFP. However, many theorists and commentators of play today would view play from a much broader perspective and argue that this should be the case within education [8]. There are also many different ways to define play, by category, criteria or by types of play, although some commentators say it is impossible to define. Within the EYFP and EYFS it is defined as 'planned purposeful play' although within the EYFP other qualities are attributed to play such as first-hand experience and experimenting. All the above ways of defining play rely on seeing play from the adult's perspective however, it has been argued that play should be viewed from the individual player's perspective, in this case children (for an overview see [10]). Viewed from this perspective play can then be defined as a form of communication, a stance taken when play is utilised for therapeutic purposes and is seen as the basis from which to establish a positive relationship.

Viewing play from children's perspectives has not been traditional practice within education however research investigating children's views of play has consistently shown differences with adult views of play. Children use environmental and social cues to differentiate between play and not play activities such as location, choice, locus of control (who is in control), adult presence, positive affect, and adult evaluation. Play activities are more likely to be ones which occur on the floor, where children have choice and control, when an adult is not present, when there is positive affect and when there is no adult evaluation. Research has also demonstrated that when children are provided with activities which fulfill their criteria of play they are enabled to feel playful and show enhanced learning and wellbeing [10].

It has been argued that listening and acting on children's views of play enables playfulness. Playfulness has been viewed as an approach or attitude that is taken towards an activity. It encompasses affective qualities, such as pleasure, involvement, motivation, concentration and enthusiasm, and are considered to be most important for development and learning. Many of these qualities are also described by the EYFP in their discussion of qualities necessary for learning through play. Overall, it can be argued that the act of play is probably less important than providing an environment based on children's views which facilitate playfulness.

Integrating theory about play and playfulness into practice requires skill and sensitivity on the part of the practitioner. Understanding play and playfulness is complex and is often cursorily addressed in training and hence practitioners lack in-depth knowledge. The case studies used in the chapter and discussed during the panel discussion demonstrated how practitioners need to understand play and playfulness theory. They need to listen to, and respect, children so they can understand their perspectives on play. Using these knowledge practitioners can create an environment which facilitates playful practice offering children time to play, space to move around and have a sense of 
freedom and choice whilst feeling in control. Practitioners who can provide this physical and emotional environment for play are more likely to be invited into children's play as co-players engaging in playful interactions which facilitate learning and development [10].

This way of facilitating play takes us back to the idea of viewing play as a form of communication. Theoretically this is the bedrock of play therapy practice and, whilst educational practitioners are not therapeutic practitioners, drawing on additional theoretical perspectives which can aid us in our practice can be beneficial. Building on this, the use of participatory learning theories has been proposed whereby teaching, learning and playing become more fully aligned [11]. In order to adopt an appropriate participatory stance, practitioners need to get to know children and their play and offer suitable play environments which facilitate playfulness this provides children with high quality, playful learning experiences.

\section{Literacy}

The aim of the chapter and panel presentation, Playing with words - becoming a reader and a writer, was to provide an overview of the fundamental importance of early literacy development as a foundation for all areas of the learning. The role that practitioners play in ensuring good quality language exposure in the Early Years is crucial in influencing both the academic and social development of the individual from infancy to adulthood. This is supported in the chapter by a number of studies which found that literacy levels in childhood were predictors of educational-vocational achievement in adult life and that low literacy levels have a strong negative impact on the transmission of poverty and social disadvantage between generations. Thus, it becomes paramount not only to have a clear understanding of the role of the practitioner but also to know how to facilitate effective communication. This becomes vital in developing successful pedagogical approaches. This is explored in detail in the chapter, which draws upon evidence from Early Year settings as examples of good practice and includes discussion around theories of emergent literacy (including acquisition of literacy by bilingual pupils or those who have English as an Additional Language), the importance of early literacy as a precursor for health and wellbeing and the evolving nature of the skills necessary to be literate in the 21 st century.

The chapter presents the underpinning theoretical perspectives as a precursor to the case studies. This provides an understanding of the key elements in the successful acquisition of fundamental literacy skills in the early years of childhood. These include the role of parents /or careers as models for language learning and the importance of high-quality early years provision, making it clear that early learning should be seen as a continuum that begins at birth and carries on through the early years and childhood. An example is the Family Champion mentioned in Case Study 2 whose sole focus is on parental engagement. This type of partnership is one element emphasised by both the Early Years Foundation Stage (EYFS) in England and the Early Years Foundation Phase (EYFP) in Wales. It is a partnership that is of fundamental importance, as recognised by the EYFP, which makes explicit that what is studied in school builds on the child's prior experiences. In addition to reinforcing cognitive understanding (i.e. the child's prior experiences), this partnership between the parents, the school and the child reinforces Vygotsky's concept of the Zone of Proximal Development (ZPD) [12] and [21], which describes the current level of the individual and the potential attainment of the next level with support from adults or peers.

Providing a framework for theoretical perspectives locates the case studies chosen within a structured context. The two cases studies were identified primarily because they offered evidence of good practice and the settings were diverse. The first case study chosen was a Welsh medium nonmaintained nursery school located in a relatively affluent semi-urban town in South-East Wales. The second case setting was a two-form-entry primary school in a deprived area of a city in the same area. Both case studies provided the opportunity to make precise and explicit connections between practice, policy and theory. The first case study demonstrates how a stimulus-response strategy can support the development of language skills (in this case Welsh as a second language), as well as the importance of routine and consistency in the application and use of language. The second case study provides an opportunity to recognise the importance of implementing programmes and schemes such as Breakfast club, the Family Champion, and 'lads and dads' reading days in educating parents from socially deprived areas about the importance of communication with their children [13]. Connecting case studies to theoretical perspectives is an approach which provides an opportunity for students and practitioners to engage with authentic pedagogical experiences which clearly and precisely locate practice within the realms of theory and policy.

The concept of drawing upon theory to illustrate evidence in practice and vice versa enables practitioners to connect with how children acquire language and enhance their own good practice. For students it provides a clear explanation of the interconnection between theory and practice, for their own use in educational settings and research. In addition, the discussion provides an opportunity to 
reflect and to consider the drivers behind current educational practice. The concept of working in partnership to draw upon theory has enabled effective discourse between practitioners and students with lecturers as facilitators for such dialogues.

While it is recognised that working in partnership and collaboratively is of extreme importance, the profound drive is the importance of understanding the complexity and challenges of providing children with access to high-quality language. Therefore, by giving children exposure to high-quality experiences of early childhood education, the impact on language acquisition, cognitive development and overall learning will be positive [1]. This is particularly true for children from economically and socially deprived backgrounds. It is estimated that children from these homes hear a difference of 153,000 words a week less when compared with children from advantaged homes [14]. The challenged often faced by practitioners, therefore, is closing the gap in educational attainment that is often created by the barriers raised when living poverty. Essential in achieving this is a clear understanding and knowledge of what constitutes effective teaching and learning. This is especially true of early literacy which should encourage children to develop language skills through rich and varied experiences of play and social interaction.

\section{Mathematics}

The mathematical section of the book and panel discussion focused on two ways in which children can be supported to confidently interpret and express their everyday experiences in a mathematical way. Both the Early Years statutory frameworks in England and Wales are seeking to develop this and there have been numerous reforms and strategies implemented which have had impact on content but more work is needed on implementation. Theorists [1] talk about groups and individuals coming to know mathematics differently and developing 'a sense of connectedness to, and a relationship with, mathematics' but in 2018 numeracy skills are still well below the average compared to other countries.

In the UK, an OECD Survey of Adult Skills [15] found that there are an estimated 9 million working aged adults in England with low literacy or numeracy skills or both. Yet Piaget felt that all children are capable of good mathematical reasoning; if you watch a child and they have ability to count, sort and recognise patterns and shapes in the early years and engage with games and activities that support mathematical reasoning. So when does mathematics become 'hard' for children and parents? Various studies in both the US and UK, reported in [1], have discussed the impact of early mathematical experiences of later mathematical use. A longitudinal study of early years pupils in the US found that early mathematics achievement predicted later mathematics attitudes and there was a potential reciprocal relation between mathematics achievement and confidence. Whilst an investigation in the UK and US looked at the impact that differing mathematics experiences can have on generations and the significant impact this can have on a child's development. The phrase 'I'm not good at maths' from adults is not uncommon. Adults would not comfortably admit to being unable to read but is it more socially acceptable to claim to be not good at mathematics? If parents/guardians are lacking in confidence then it is important that we engage children, parents and teachers in collaborative approach to developing confidence in mathematics.

Both the Foundation Phase and Foundation Stage set out expectations for mathematics and numeracy and there are particular challenges being focused on: curriculum design, changing perceptions, professional development of both new and current practitioners and ensuring that interventions are timely and appropriate when children are struggling with numeracy. At the early stage of a child's development, parents can play a critical role in both development and confidence. Working in partnership with parents can be the most effective means of ensuring coherence and continuity in children's experiences, and in the curriculum offered to them. This concept of 'authentic' learning is being seen as a critical throughout the learner's journey from early years to university level. The links to active learning are clear to see as children are encouraged be resilient if they encounter challenges and importantly enjoy achievements.

\subsection{Using Apps to support shared learning.}

Everyday experiences are an excellent source for genuine mathematical problem solving and practice and mobile technologies can be an effective way to support children and parents to work together. An example of successful practice is researching and providing apps for children to use with their parents. Extensive work has been carried out looking at the value of apps and mathematical learning and stresses the role they alternative ways to facilitate understanding in an active and exploratory way [16].

There is a wealth of apps that have both a direct and indirect link to mathematical concepts. Maths 35 and Maths 4-6 has been trialled by Nottingham University and positive results about engagement, confidence and skills acquirement were reported. This was an ideal app to use in partnership with parents and could be linked in with school activities very easily. Apps can be reviewed and be a part of classroom and home activity and there is an opportunity for the teacher, child and parent to share information about the apps they are discovering. 
This joint development of a shared resource can develop confidence in all involved.

\subsection{The importance of the home learning environment.}

One study looked at empowering parents to support their children's mathematics learning [17]. The study considered mathematics as a part of everyday life and although the main focus was years 3 and 4 (7-9 years of age), it has generated important findings for early years practitioners and generated practical resources. The main findings are:

- Using mathematics outside school can improve attitude and confidence in the concepts

- Children need regular contact with mathematical concepts and this can be done in the home with guidance.

- Schools should explore ways in which they can work in partnership with parents. An important point made in the research that this is not about parents having extensive mathematical knowledge.

Mathematics learning should be a positive environment for the teacher, parent and child. Our ability to engage with mathematical concepts can have a significant impact on our life chances. From working with practitioners and student teachers and considering existing research it has been reported that there are two key factors that impact on a child's engagement with mathematical concepts:

- Early encounters with mathematics develops confidence in ability to understand and use mathematics.

- Positive experiences help children to develop: curiosity, imagination, flexibility, inventiveness, and persistence

This research confirms that and would also add:

- Experiences should not be limited to the classroom and parents should be encouraged to be involved in their child's mathematical development and possibly their own too [1].

Educators must be proactive and scaffold the learning in a way which is sympathetic to the learner's needs and also develop confidence where needed in parents too. The aim is to work in partnership and co-construct meaning with the child and the parent working with the teacher. As a child develops, the teacher and curriculum should facilitate ways for parents and children to develop confidence together and explore ways to build on and enhance children's natural mathematical thinking through play, technology and everyday activities.

\section{Science}

As Moyles [18] postulates, 'Play and playful experiences can provide opportunities for children to sustain and develop their natural curiosity'. These are the skills required for children to become scientists and 'come to know' the world around them. Science is located within the Knowledge and Understanding of the World area of learning in both the Welsh and English early years curricula. The chapter and panel discussion discussed how children are encouraged to be hands on learners with supportive adults and peers encouraging the development of key scientific skills such as exploration, investigation and enquiry. Science is a subject that lends itself very well to "learning by doing' through investigating and exploring. Through experiential activities children become scientists, enhancing their cognitive development, communication skills and scientific understanding through the development of thinking skills. Children need to take ownership and be active in gathering understanding of the world we live in. They need to do this by building upon previous experience and knowledge [19]. Science is all about testing out ideas and theories and communicating with each other.

In the Foundation Phase documentation guidance for 'Knowledge and Understanding of the World' it states that, 'Children will be provided with meaningful experiences... they will undertake investigations that engage their interests' [20]. Children are encouraged to explore and investigate through a number of different ways including observation, questioning, exploring and classifying. Practitioners have a responsibility to become scientific implementers, allowing children to work with their peers, to explore and discover different methods of thinking and learning whilst offering support and guidance where needed. This can be through 'playing' alongside the children and asking appropriate open ended questions, allowing children the time and space to think. This process of asking questions, observing and listening to children's responses links into the theories of Vygotsky [21]. Vygotsky believed that children needed to talk about their thought and ideas with interested adults. This is congruent with the theories of Bruner who stated that active social interaction with children, learning alongside their peers appears to be the most effective means of early scientific learning. This supportive approach appears in contrast to the theories of Piaget who placed little emphasis on the role of the teacher. He used the term, 'lone scientist' when describing a 
child who learns through practical experience on their own. For Piaget, the teacher's role was to solely provide and manage a suitable learning environment, whereas Vygotsky and Bruner argued that the teacher had a central role.

In practice, there is evidence of Vygotsky, Bruner and Piaget's theories in action. Settings will often introduce new scientific concepts through lots of initial support from practitioners. Children will often work alongside practitioners and peers in experiential activities. The practitioners will share the learning objectives with the children, ask questions, have an open dialogue with the children and scaffold children in their scientific endeavors. The children are encouraged to share their thoughts and ideas aiding the development of their thinking skills. Scientific vocabulary is shared and reinforced throughout and is displayed, alongside children's work so there is a continual visual reference for the children to refer to. The teachers encourage the children to think of themselves as independent learners and thinkers, as well as collaborative partners throughout the science lessons.

Additionally, there are opportunities for children to become the 'lone scientist' that Piaget proposed. Practitioners allow the children time to return to scientific activities on their own and to carry on their explorations. Most classrooms will have a 'Discovery' area or table where children can carry on their investigations in their own time. This allows children to take ownership of their understanding and 'coming to know' the world around them. Children are naturally curious and this curiosity needs to be harnessed in the early years and onwards.

Science is all about testing out ideas and theories and communicating with each other, enabling children to become scientific thinkers and pioneers. Practitioners have a responsibility to become scientific facilitators, encouraging children to work alongside their peers and independently to explore and discover new ways of thinking and learning. In this way, practitioners share the learning journey with the children and provide them with those experiential opportunities that foster curiosity and enable them to become their own scientists.

\section{Student voice}

Both the book and the panel discussion argued for the need to link theory and practice when teaching early years students. A key aspect of the book and the panel discussion was to highlight the fact that much of the literature available for students concentrates on theory without setting this theory in meaningful contexts. During the panel discussion we argued how providing real-life case studies and modelling collaborative practice between practitioners and academics could be beneficial for student's developing understanding of early years practice. However, at the time of the panel discussion this was largely a theoretical proposition. Therefore, a short student survey, using Survey Monkey, of early years of student's using the book within one of the academic institutions where a number of the authors teach was undertaken.

Student evaluation of taught modules is routinely undertaken at the end of every taught module. As a part of the student evaluation for one taught early years' module, supplementary questions were asked relating to their use of the book. The 21 students responded to the survey and stated that they used the book in a variety of ways, mostly as one would expect students to use any textbook; to support essay content, for wider reading around the subject, to support their understanding of a particular topic and for referencing, both referencing within their work and an exemplar of referencing. Students also reported that it enabled them to 'understand concepts' and 'strengthen their understanding'. They reported that case studies were helpful in developing their understanding and 'grounded my knowledge and understanding of the topic'. An important aspect for these students was that they really 'appreciated the focus on the Welsh Foundation Stage', something not seen in other textbooks.

Having a book written by tutors who taught them was also seen as important. They felt they had 'more in-depth learning straight from them' and that 'it's almost like having extra class time'. They felt that because it was written by their lecturers that 'you can trust the resource' and 'you know it's reliable' something students often feel confused about when choosing literature sources. They also recognized that they were being taught by 'research active staff' and that the information contained within the book related research, theory and practice. One unexpected outcome was the comments related to student's feelings about the course. More than one student stated they felt 'proud and confident' and that it gave 'kudos for the course'.

\section{Discussion}

The aim of the panel discussion was to integrate both the 'why' and the 'how' of early years' education by giving a theoretical background to areas of the curriculum combined with examples of how this looked in the practice. As previously stated, in order for early years students to develop appropriate and high quality practice they need to reflect critically on theory and integrate this into their practice. By doing this they develop a deep understanding of early years practice which is beneficial for children's development and learning, not only in the here and now, but also in the future.

Utilising the Welsh Foundation Phase and comparing and contrasting this with the English Foundation Stage has had advantages as the Welsh 
Curriculum covers an age range which extends into the younger primary age phase. It is also holistic and based on active and experiential learning. For those students studying, and ultimately practising, within Wales, this represents one of the very few books which applies to their context. The unique approach to writing with practitioners and academics working together provides a role model for students regarding collaborative working and ensures that the case studies used to exemplify theory are current and relevant, something students appreciate.

Overall, the approach taken within the book and presented in the panel discussion has been beneficial to student's learning and understanding of early years theory. They recognize that the integration of research theory and practice demonstrated in the book has enhanced their understanding of theoretical concepts which they can demonstrate in their written assignments and apply in their practice. It has also enhanced their appreciation of their course, the lecturers who teach them and the practitioners they encounter in the field.

\section{References}

[1] Thomas, A, and McInnes, K, (Eds) (2017). Teaching Early Years Theory and Practice, Sage, London.

[2] QAA, (2014). Subject Benchmark Statement Early Childhood Studies, http://www.qaa.ac.uk/en/Publications/ Documents/ SBS-early-childhood-studies-14.pdf (Access Date: 16 February, 2018).

[3] Payler, J, and Davis, G., (2017). Professionalism: Early Years as a Career, BERA-TACTYC Early Childhood Research Review 2003-2017, https://www.bera.ac.uk/wpcontent/up loads/2017/05/BERA-TACTYC-Full-Report.p df?noredir ect=1 (Access Date: 16 February, 2018).

[4] Koc, K., (2012). "Using a dilemma case in early childhood teacher education: Does it promote theory and practice connection?" Educational Sciences: Theory and Practice, Autumn, pp. 3152-3163.

[5] Department for Education (DfE), (2014). Statutory Framework for the Early Years Foundation Stage. https://www.gov.uk/government/uploads/system/uploads/a ttachment_data/file/335504/EYFS_framework_from_1_Se ptember_2014_with_clarification_note.pdf (Access Date: 19 August 2016).

[6] Welsh Government (WG), (2015). Framework for Children's Learning for 3--7 year olds in Wales (Revised), Welsh Assembly Government, Cardiff.

[7] Cameron, C., (2006). New Ways of Educating: Pedagogy and Children's Services, Sage, London.

[8] Wood, E, Play, Learning and the Early Childhood Curriculum, Sage: London, (2013).
[9] Thomas, A., and Lewis, A., (2016). An Introduction to the Foundation Phase Early Years Curriculum in Wales, Bloomsbury, London.

[10] Howard, J., and McInnes, K., (2013). The Essence of Play, Routledge, Abingdon,

[11] Walsh, G., McGuinness, C., and Sproule, L., (2017). "It's teaching... .but not as we know it: using participatory learning theories to resolve the dilemma of teaching in play-based practice", Early Child Development and Care, DOI: 10.1080/03004430.2017.1369977.

[12] Vygostky, L.S., (1978). Mind in Society: The Development of Higher Psychological Processes, Harvard University Press, Cambridge, MA,

[13] Welsh Government, (2014). Rewriting the Future: Raising Ambition and Attainment in Welsh Schools, Welsh Government, Cardiff.

[14] Sticht, T., (2012). "Getting it right from the start: The case for early parenthood education", American Educator, www.aft.org/sites/default/files/periodicals/Sticht.pdf (Acc -ess Date: 12 February 2018).

[15] OECD Skills Outlook (2013) First Results from the Survey of Adult Skills. OECD Publishing, Paris. DOI: 10.1787/9789264204256-en.

[16] Calder, N, and Campbell, A., (2016). "Using mathematical apps with reluctant learners", Digital Experiences in Mathematics Education, 2 (1), pp. 50-69.

[17] Jay, T., Rose, J., and Simmons, B., (2013). "Why parents can't get what they (think they) want", Proceedings of the British Society for Research in Learning Mathematics, November,

[18] Moyles, J., (Ed.), (2011). Beginning Teaching Beginning Learning, McGrawHill, Berkshire,

[19] Welsh Assembly Government (WAG), (2008). Knowledge and Understanding of the World. Welsh Assembly Government, Cardiff.

[20] Piaget, J., (1929). The Child's Conception of the World, Harcourt, New York.

[21] Vygotsky, L. S., (1999). The collected works of LS. Vygotsky. Scientific Legacy (M.J.) 6. 